\title{
Heliconia psittacorum: Hospedeira de Mycosphaerella fijiensis, Agente Causal da Sigatoka-Negra da Bananeira
}

\author{
Luadir Gasparotto ${ }^{1}$, J. Clério R. Pereira' ${ }^{1}$ Arailde F. Urben ${ }^{3}$, Rogério E. Hanada ${ }^{2}$ \\ \& Mirza C. N. Pereira ${ }^{1}$
}

'Embrapa Amazônia Ocidental, Cx. Postal 319, CEP 69011-970, Manaus, AM, e-mail:gasparot@cpaa.embrapa.br; ${ }^{2}$ INPA, Cx. Postal 478, CEP 69011-970, Manaus, AM; ${ }^{3}$ Embrapa Recursos Genéticos e Biotecnologia, Cx. Postal 02372, CEP 70770-900, Brasília, DF

(Aceito para publicação em 30/05/2005)

Autor para correspondência: Luadir Gasparotto

GASPAROTTO, L., PEREIRA, J.C.R., URBEN, A.F., HANADA, R.E. \& PEREIRA, M.C.N. Heliconia psittacorum: hospedeira de Mycosphaerella fijiensis, agente causal da sigatoka-negra da bananeira. Fitopatologia Brasileira 30:423425. 2005.

\section{RESUMO}

Em setembro de 2003, em Manaus, Amazonas, foram observadas manchas foliares, muito semelhantes àquelas de sigatoka-negra causada por Mycosphaerella fijiensis em folhas de Heliconia psittacorum. Efetuou-se o isolamento do patógeno e, para o teste de patogenicidade, foi utilizada a técnica de inoculação cruzada com os isolados de $H$. psittacorum e de bananeira (Musa spp.) da cv. Prata Anã. Em ambas as espécies o teste foi positivo. Com o auxílio do microscópio óptico, da literatura disponível e dos testes de patogenicidade, confirmou-se que H. psittacorum é hospedeira de $M$. fijiensis, sendo este o primeiro relato da ocorrência de M. fijiensis em helicônias.

Palavras-chave adicionais: helicônia, patogenicidade, mancha foliar.

\section{ABSTRACT}

First reporter of Mycosphaerella fijiensis on Heliconia psittacorum leaves

In Manaus - Amazon, Brazil, in September 2003, spots on leaves of Heliconia psittacorum were observed that were very similar to those of black sigatoka caused by Mycosphaerella fijiensis on Musa spp. The pathogen was isolated and a pathogenicity test was done. An isolate from H. psittacorum and other from banana (Musa spp.) cv. Prata Anã were inoculated on $H$. psittacorum as well as on banana cv. Prata Anã. In both species the tests were positive. Microscopic observations and the results of pathogenicity tests showed that H. psittacorum is another host of M. fijiensis. This is the first report of M. fijiensis on H. psittacorum.

Additional keywords: heliconia, pathogenicity, leaf spot.

A sigatoka-negra, causada pelo fungo Mycosphaerella fijiensis Morelet (fase anamórfica: Paracercospora fijiensis (Morelet) Deighton), é a doença mais grave da bananeira (Musa spp.), cujas perdas nas cultivares suscetíveis podem atingir $100 \%$ da produção. No Brasil, a doença foi identificada em fevereiro de 1998 nos Municípios de Tabatinga e Benjamim Constant, no Estado do Amazonas, fronteira do Brasil com a Colômbia e Peru (Pereira et al., 1998). Encontrava-se disseminada nos Estados do Amazonas, Acre, Rondônia, Mato Grosso, Pará, Roraima e Amapá (Gasparotto et al., 2001) e recentemente atingiu os Estados de São Paulo, Paraná, Santa Catarina, Rio Grande do Sul, Mato Grosso do Sul e Minas Gerais (Ferrari et al., 2005 a, 2005 b, 2005 c; Nogueira et al., 2005).

Em setembro de 2003, todas as plantas de Heliconia psittacorum L. situadas no jardim da Embrapa Amazônia Ocidental, em Manaus, Amazonas, apresentavam sintomas semelhantes aos da sigatoka-negra da bananeira. Heliconia psittacorum, pertencente à família Heliconiaceae (Castro, 1995), é um arbusto rizomatoso, entouceirado, com 1,5 a 2 $\mathrm{m}$ de altura. É uma das espécies de helicônia mais cultivadas comercialmente. As folhas são ovalada-lanceoladas, coriáceas e com pecíolo curto. As inflorescências (Figura 1), muito duráveis, são curtas, com hastes longas, eretas e brácteas com forma de barco, finas, sendo suas bases mais longas, vermelhas e amarelas, produzidas durante todo o ano (Harri \& Souza, 1995).

Inicialmente são observados pontos cloróticos nas folhas, mais facilmente perceptíveis quando o limbo foliar é colocado contra a luz. Posteriormente, ocorre expansão dos pontos cloróticos dando origem a lesões ligeiramente arredondadas de coloração amarela na face adaxial e creme na face abaxial. Nesse estádio, as lesões são mais facilmente visualizadas na face adaxial. As lesões crescem radialmente, adquirindo coloração marrom-clara com bordos proeminentes, de coloração amarela na face abaxial e amarelo-clara na face adaxial. Em seguida, na face abaxial as lesões adquirem, em toda sua extensão a coloração marrom, com subseqüente redução do halo amarelo. Na mesma área correspondente, na face adaxial, forma-se uma coloração amarela mais intensa. A partir desse estádio, as lesões expandem-se radial e longitudinalmente, adquirindo 
coloração marrom-escura na face abaxial e centro marromclaro com halo proeminente na face adaxial (Figura 2). Em seguida, as lesões de coloração marrom-escura, de formato ligeiramente elíptico, podem coalescer, e o limbo torna-se marrom na face abaxial e clorótico em toda sua extensão na face adaxial devido à coalescência de lesões com halo amarelo proeminente. Com o progresso, as lesões na face adaxial tornam-se marrom-claras. A partir desse estádio, inicia-se o amarelecimento do limbo foliar no sentido do ápice para a base. A face abaxial torna-se marrom a partir do ápice e a face adaxial adquire tonalidade amarelo-intensa. Mesmo nos estádios finais da doença não ocorre necrose do limbo foliar na área das lesões, e as lesões de coloração marrom-escura apresentam-se com formato alongado do tipo elipse. A senescência não ocorre de forma individualizada na área correspondente à lesão, mas em todo o limbo foliar, que se mostra desidratado. Finalmente, todo o limbo adquire, na face abaxial, coloração palha (cinza com manchas castanhas marrom-acinzentadas) e, na face adaxial, marrom-clara em toda a extensão do limbo.

Este trabalho tem por objetivo relatar, pela primeira

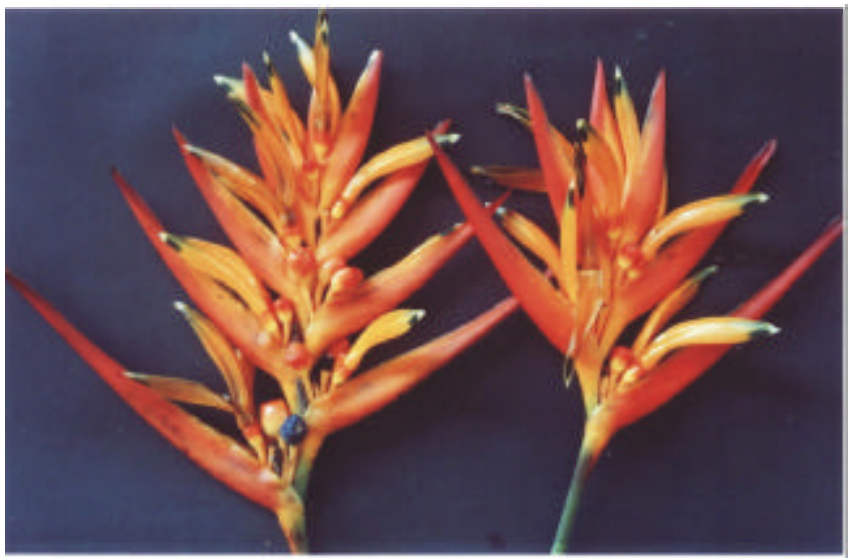

FIG. 1 - Inflorescências de Heliconia psittacorum.

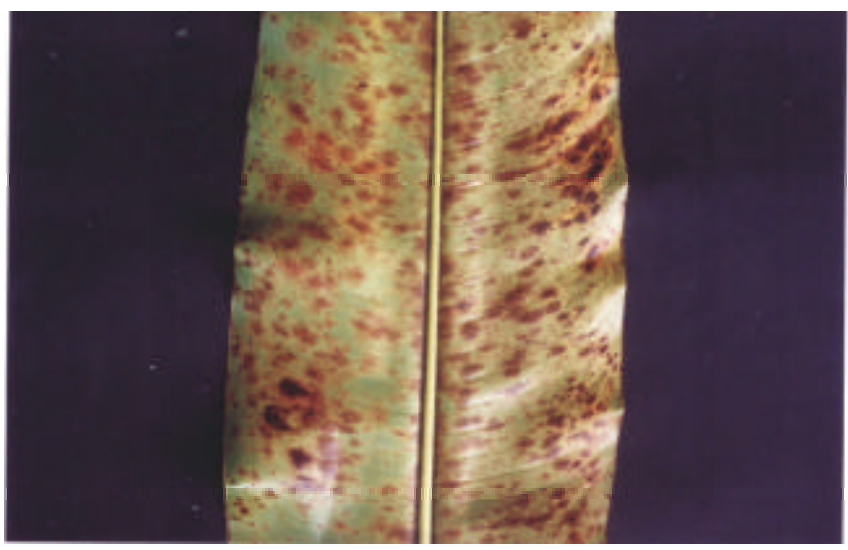

FIG. 2 - Manchas em folhas de Heliconia psittacorum causadas por Mycosphaerella fijiensis. vez, a ocorrência do fungo $M$. fijiensis causando doença em helicônia.

$\mathrm{O}$ isolamento do $M$. fijiensis foi realizado a partir de lesões nas folhas, retirando-se fragmentos de cerca de $3 \mathrm{~mm}$ da região limítrofe entre o tecido doente e o tecido sadio. Os fragmentos foram desinfestados em hipoclorito de sódio $0,5 \%$, por 2 a 3 min, e então implantados em placa de Petri contendo ágar-água e, após o crescimento de hifas, transferiram-se discos de cultura para meio BDA.

O M. fijiensis isolado da $H$. psittacorum apresenta conidióforos isolados ou em pequenos grupos, marromoliváceos, retos ou curvos; conídios sub-hialinos a oliváceos, cilindro-obclavados, retos ou curvos, com um a dez septos (maioria com cinco septos), medindo 38,4 - 120,0 x 2,40 3,60 $\mu$ de diâmetro, base arredondada com hilo protuberante, características anátomo-morfológicas idênticas às descritas na literatura (Mulder \& Holliday, 1974; Frossard et al., 1980).

O teste de patogenicidade foi feito utilizando os isolados oriundos da $H$. psittacorum e da bananeira cv. Prata Anã, inoculando-os na $H$. psittacorum e na cv. Prata Anã, através de técnica de inoculação cruzada. Os conídios foram produzidos em meio de BDA, segundo metodologia descrita por Hanada et al. (2002). A partir da produção dos conídios, procedeu-se a inoculação de plantas mantidas em sacos de polietileno preto, pulverizando a suspensão de conídios na concentração de $2 \times 10^{5}$ esporos. $\mathrm{ml}^{-1}$ acrescido de Tween (uma gota para cada $100 \mathrm{ml}$ ), em ambas as faces das folhas com no máximo uma semana após emissão. Foram inoculadas quatro plantas de cada espécie, para cada isolado. Logo após a inoculação, as plantas foram mantidas em condições de câmara úmida por um período de 48 h. O aparecimento dos sintomas ocorreu a partir dos 52 dias após a inoculação. $\mathrm{O}$ reisolamento obtido das plantas inoculadas apresentou as mesmas características das culturas originais. Os dois isolados de $M$. fijiensis foram patogênicos à $H$. psittacorum e à bananeira cv. Prata Anã.

Os resultados positivos das inoculações cruzadas indicam que $H$. psittacorum pode atuar como veículo de disseminação do M. fijiensis a longas distâncias, principalmente quando suas flores são exportadas para regiões do País onde não ocorre a doença.

\section{REFERÊNCIAS BIBLIOGRÁFICAS}

CASTRO, E.F. Helicônia para exportação: aspectos técnicos de produção. Brasília: Embrapa/SPI. (Série Publicações Técnicas. FRUPEX; 16). 1995.

FERRARI, J.T., HARAKAVA, R., NOGUEIRA, E.M. de C. \& CASTRO, M.E.A. Ocorrência de sigatoka-negra da bananeira no Sul de Minas Gerais. Summa Phytopathologyca 31:34. 2005a. (Resumo)

FERRARI, J.T., NOGUEIRA, E. M. de C., GASPAROTTO, L. \& HANADA, R.E. Ocorrência de sigatoka-negra em bananeiras no Estado de São Paulo. Summa Phytopathologyca 31: 33. 2005 b. (Resumo) 
FERRARI, J.T., TOMAZ, R., HARAKAVA, R. \& NOGUEIRA, E.M. de C. Sigatoka-negra da bananeira no Estado do Paraná. Summa Phytopathologyca 31:102. 2005c. (Resumo)

FROSSARD, P. Apparition d'une nouvelle et grave maladie foliare des bananiers et plantains au Gabon: la maladie des raies noires: Mycosphaerella fijiensis Morelet. Fruits 9:519-527. 1980.

GASPAROTTO, L., PEREIRA, J.C.R. \& TRINDADE, D.R. Situação atual Sigatoka negra da bananeira. Fitopatologia Brasileira 26:449. 2001. (Resumo).

HANADA, R.E., GASPAROTTO, L. \& PEREIRA, J.C.R. Esporulação de Mycosphaerella fijiensis em meio de cultura. Fitopatologia Brasileira 27:170-173. 2002.
HARRI, L. \& SOUZA, H.M. Plantas ornamentais no Brasil: arbustivas, herbáceas e trepadeiras. Nova Odessa: Editora Plantarum, 1995.

MULDER, J.L. \& HOLLIDAY, P. Mycosphaerella fijiensis. CMI Descriptions of pathogenic fungi and Bacteria $n^{\circ}$ 413. CMI. 1974. NOGUEIRA, E.M. de C., FERRARI, J.T. \& HARAKAVA, R. Sigatoka-negra Mycosphaerella fijensis em bananeira no Mato Grosso do Sul. Summa Phytopathologyca 31: 34. 2005. (Resumo) PEREIRA, J.C.R., GASPAROTTO, L., COELHO, A.F.S. \& URBEN, A.F. Ocorrência da Sigatoka negra da bananeira no Brasil. Fitopatologia Brasileira 23:295. 1998. (Resumo). 